
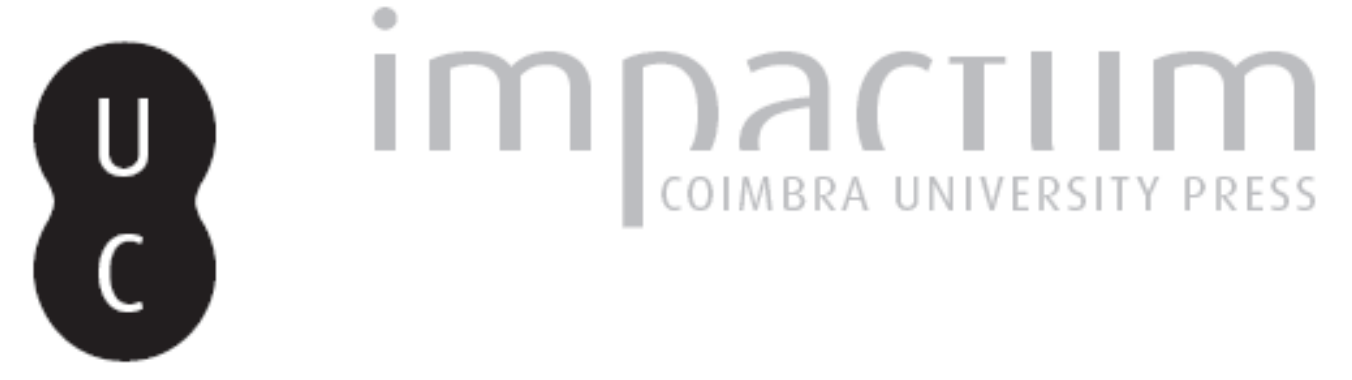

\title{
Percepção dos danos após inundação nos concelhos de Arcos de Valdevez e Ponte da Barca entre 1900 e 2007
}

Autor(es): $\quad$ Gonçalves, Glória

Publicado por: Associação Portuguesa de Riscos, Prevenção e Segurança

URL persistente:

URI:http://hdl.handle.net/10316.2/36077

DOI:

DOI:http://dx.doi.org/10.14195/1647-7723_18_21

Accessed : $\quad$ 26-Apr-2023 15:14:22

A navegação consulta e descarregamento dos títulos inseridos nas Bibliotecas Digitais UC Digitalis, UC Pombalina e UC Impactum, pressupõem a aceitação plena e sem reservas dos Termos e Condições de Uso destas Bibliotecas Digitais, disponíveis em https://digitalis.uc.pt/pt-pt/termos.

Conforme exposto nos referidos Termos e Condições de Uso, o descarregamento de títulos de acesso restrito requer uma licença válida de autorização devendo o utilizador aceder ao(s) documento(s) a partir de um endereço de IP da instituição detentora da supramencionada licença.

Ao utilizador é apenas permitido o descarregamento para uso pessoal, pelo que o emprego do(s) título(s) descarregado(s) para outro fim, designadamente comercial, carece de autorização do respetivo autor ou editor da obra.

Na medida em que todas as obras da UC Digitalis se encontram protegidas pelo Código do Direito de Autor e Direitos Conexos e demais legislação aplicável, toda a cópia, parcial ou total, deste documento, nos casos em que é legalmente admitida, deverá conter ou fazer-se acompanhar por este aviso.

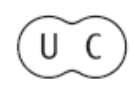




\section{territorium}

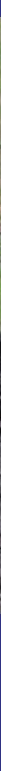

\section{Afirmar as Ciências Cindínicas}

Revista da Associação Portuguesa de Riscos, Prevenção e Segurança 


\section{RESUMO}

Com este trabalho pretende-se dar um contributo no sentido de classificar e quantificar os danos ou efeitos adversos após a ocorrência de inundações ribeirinhas nos concelhos de Arcos de Valdevez e Ponte da Barca. A principal fonte de informação foi baseada num inventário existente, obtido dos periódicos regionais. Como objectivos pretende-se verificar a importância dos periódicos como fonte de informação sobre a percepção de danos causadas pelas inundações, para poder classificar e quantificar a evolução histórico-geográfica dos danos nas áreas territoriais de risco. A informação será apresentada em gráficos e esboços cartográficos para identificação e localização dos danos.

Palavras-chave: Inundações, percepção, danos, periódicos.

\section{RESUMEN}

Percepción de Daños por Inundación en los Municipios de Arcos de Valdevez Y Ponte da Barca entre 1900 A 2007 - Con este trabajo se pretende dar una contribución para la clasificación y cuantificación de los daños o efectos adversos a consecuencia de inundaciones de los ríos en los municipios de Arcos de Valdevez y Ponte da Barca. La fuente principal de información fue tomada de una base de datos construida a partir de los periódicos regionales. Se trata de verificar la importancia de los periódicos como fuente de información en lo que a percepción de daños se refiere, causados por inundaciones, para poder clasificar y cuantificar la evolución histórico-geográfica de los daños en las áreas territoriales de riesgo. La información será presentada en gráficos y esbozos cartográficos para la identificación y localización de daños. Palabras claves: Inundaciones, percepción, daños periódicos.

\section{RÉSUMÉ}

Perception des dégâts suite à inondation dans les Comtés de Arcos de Valdevez et Ponte da Barca de 1900 à 2007 - Avec cet étude on a comme objectif de contribuer en vue de classifier et quantifier les dégâts ou effets indésirables suite à l'évènement d’inondations marginales dans les Comtés de Arcos de Vadevez et Ponte da Barca. La principale source d 'information est basée dans un inventaire existant, obtenu grâce aux journaux régionaux. Comme objectifs, nous prétendons vérifier l’importance des journaux comme source d information sur la perception des dégâts causés par les inondations, pour pouvoir classifier et quantifier l’évolution historico-géographique des dégâts dans les surfaces territoriales à risques. L`information sera présentée en graphiques et croquis cartographiques pour identification et localisation des dégâts.

Mots Clés: inondations, perception, dégâts, journaux.

\section{ABSTRAT}

Perception of Flooding Damage at Arcos de Valdevez and Ponte da Barca Municipalities in the Period 1900-2007 - This paper aims to contribute with the classification and quantification of damages or adverse effects produced by river flooding in Arcos de Valdevez and Ponte da Barca municipalities. The main source of information was a data base build up from regional newspapers. The main objective is to verify the usefulness of the newspapers' perception information to classify and quantify the historical-geographical evolution of damages in the risk areas. The information is presented in graphics and cartographic schemes for identification and localization of damages.

Key words: flooding, perception, damage, newspapers.

\footnotetext{
* O texto deste artigo corresponde à comunicação apresentada ao II Congresso Internacional de Riscos e VI Encontro Nacional, tendo sido submetido para revisão em 29-06-2010, tendo sido aceite para publicação em 04-08-2010. Este artigo é parte integrante da Revista Territorium, n. ${ }^{\circ}$ 18, 2011, ® RIsCOS, ISBN: 0872- 8941.
} 


\section{Introdução}

A prevenção de danos provocados por inundações ribeirinhas exige investigação contínua, por unidades de risco à escala local, importante na tomada de decisões de investimento, manutenção e modificações das inundações através do controle estrutural. Além disso, exige preparação institucionais e privadas (C. HAQUE, 2000).

As perdas económicas devidas a inundações continuam a subir. Os dados mostram que as perdas estão ligadas ao aumento da construção de edifício e estruturas em áreas de risco. Esta crescente vulnerabilidade junto a áreas ribeirinhas levanta questões sobre o método de avaliação de riscos, sendo os danos uma das variáveis chave para os compreender.

Os danos devidos a inundações devem ser evitados o mais possível H. KREIBICH, et al, (2005), uma vez que, a protecção absoluta contra inundações em áreas ribeirinhas de risco não existe. Para melhorar o conhecimento fizemos uma pesquisa sobre os danos associados a inundações que causaram preocupação nos concelhos de Arcos de Valdevez e Ponte da Barca, especialmente nas sedes de concelho ocupadas por edifícios residenciais e/ou comerciais nas margens ribeirinhas.

\section{Objectivos}

A partir da informação dos jornais (datados de 1900 a 2007), dos concelhos de Arcos de Valdevez e Ponte da Barca, pretende-se sistematizar os tipos de danos e a sua localização; Apresentar a percepção da magnitude dos danos; Apresentar as principais causas; e contribuir com alguns elementos para a avaliação dos periódicos como fonte de informação sobre a percepção de danos causados por inundações.

\section{Metodologia}

1. Identificação dos jornais locais mais representativos dos dois concelhos;

2. Identificação dos critérios para a sistematização da informação;

3. Delineamento de uma ficha de registo de danos;

4. Representação gráfica da percepção dos danos e sua magnitude. Representação cartográfica da localização geográfica dos danos.

A sistematização dos danos, segundo G. Pellegrina, et al, (2009) deve representar classes hierarquicamente organizadas de acordo com as variáveis escolhidas. Tendo em consideração alguns critérios, decidimos ordenar a ocorrência de danos (materiais, humanos e ambientais) em função de cada ano hidrológico e de cada evento ocorrido. Para tal, como procedimento metodológico, as informações foram digitadas por data de ocorrência em cada ficha de registo. Assim sendo, utilizamos esta estratégia para registar e consultar o histórico-geográfico de danos.

A grelha de registo das variáveis foi delineada, tendo em consideração o tipo de danos, por grupos, verificados na área de estudo (TABELA I). Registamos se o atributo foi atingido ou não, a quantidade, duração, magnitude, local (Concelho, Freguesia ou Lugar) e algumas informações adicionais que consideramos importantes.

A ficha de registo aplica-se para a área de estudo, logo a sua utilização noutras áreas de risco merece algumas adaptações para acréscimo de outras variáveis existentes e que sofreram danos, de forma a obter informação com detalhe.

Tabela I - Demonstração de um esboço da ficha de registo delineada para representar os danos segundo as variáveis em função da sua tipologia por data de ocorrência.

\begin{tabular}{|c|c|}
\hline Edifícios & $\begin{array}{l}\text { Habitações } \\
\text { Comércio } \\
\text { Indústria } \\
\text { Edifícios de serviço público } \\
\text { Edifícios históricos públicos }\end{array}$ \\
\hline Locais públicos & $\begin{array}{l}\text { Vias de comunicação (EN, Ruas, Pontes) } \\
\text { Áreas de lazer (jardins e parques) } \\
\text { Parques de estacionamento } \\
\text { Praia fluvial } \\
\text { Áreas para comércio (feiras ou mercado) } \\
\text { Áreas culturais (eventos religiosos) }\end{array}$ \\
\hline Serviços & $\begin{array}{l}\text { Comunicações (telefones, rádio, televisão, outros) } \\
\text { Electricidade } \\
\text { Sistema de fornecimento de água } \\
\text { Gás } \\
\text { Esgotos } \\
\text { Escoamento pluviais (caleiras e sarjectas) } \\
\text { Transportes }\end{array}$ \\
\hline Agrícolas e florestal & $\begin{array}{l}\text { Gado (morte de animais) } \\
\text { Culturas agrícolas } \\
\text { Perda de equipamentos ou produtos } \\
\text { Árvores (queda) } \\
\text { Propriedades agrícolas (muros, Valados) }\end{array}$ \\
\hline Humanos & $\begin{array}{l}\text { Desalojados e/ou evacuados } \\
\text { Perdas de vidas }\end{array}$ \\
\hline $\begin{array}{l}\text { E c o n ó m i c o s } \\
\text { (contabilizados) }\end{array}$ & $\begin{array}{l}\text { Danos públicos } \\
\text { Custos públicos de recuperação e limpeza } \\
\text { Custos particulares contabilizados }\end{array}$ \\
\hline
\end{tabular}

Todos os documentos consultados (TABELA II) foram analisados atentamente e consideradas as datas em arquivo. É de salientar, como se confirma na TebeLA II, entre 1904 a 1906 não foi possível consulta de dados por falta de periódicos. 
TABELA II - Origem da principal fonte de informação sobre os danos.

\begin{tabular}{|l|l|}
\hline Periódicos & Datas consultas \\
\hline Notícias dos Arcos & $1900-1904$ \\
Falta de periódicos & $1904-1906$ \\
Jornal Arcoense & $1907-1910$ \\
Alvorada e Alvorada do Vez & $1910-1915$ \\
Regionalista & $1915-1919$ \\
Concórdia & $1919-1931$ \\
Jornal dos Arcos & $1931-2007$ \\
O Povo da Barca & $1900-2007$ \\
Notícias da Barca & 1987 \\
\hline
\end{tabular}

\section{Resultados e discussão}

A elaboração de uma carta de localização de danos dá-nos o panorama das unidades expostas ao risco. Para melhor percepcionarmos os dados sobre a fragilidade ao risco apresentamos a Fig. 1 a localizar os danos obtidos segundo os periódicos na área em estudo.
As áreas com maior risco fazem parte das sedes de concelho, localizadas nas margens dos rios Vez e do Lima. Da consulta efectuada, registamos vários danos em diferentes locais. Em Arcos de Valdevez, foram identificados alguns dos locais, como sejam, Guilhadeses, São Jorge, Paçô, Arcos de Valdevez (São Paio), Valeta, Gondoriz, Couto, Prozelo, Rio Frio, Giela, Vale, Vila Fonche, Junto à Ponte sobre o Rio Vez, Ínsua do Vez, Trasladário, Jardim dos Centenários. Em Ponte da Barca, temos dados precisos, como sejam, Curro, Rua Dr. Sousa, Fonte Velha, Largo da Lapa, Rua José Lacerda, Bravães, Jardim dos Poetas, Painçães, Igreja, Vila Nova de Muia, Lavradas, Ponte sobre o Rio Lima. É importante acrescentar que a maioria dos danos não foram devidamente localizados, apenas referia no artigo do periódico "os danos ocorreram por todo o concelho", logo, não podemos localizar no esboço cartográfico. No entanto, temos uma ideia geral dos danos mais importantes ocorridos que se deveram às inundações, especialmente, em edifícios e arruamentos.

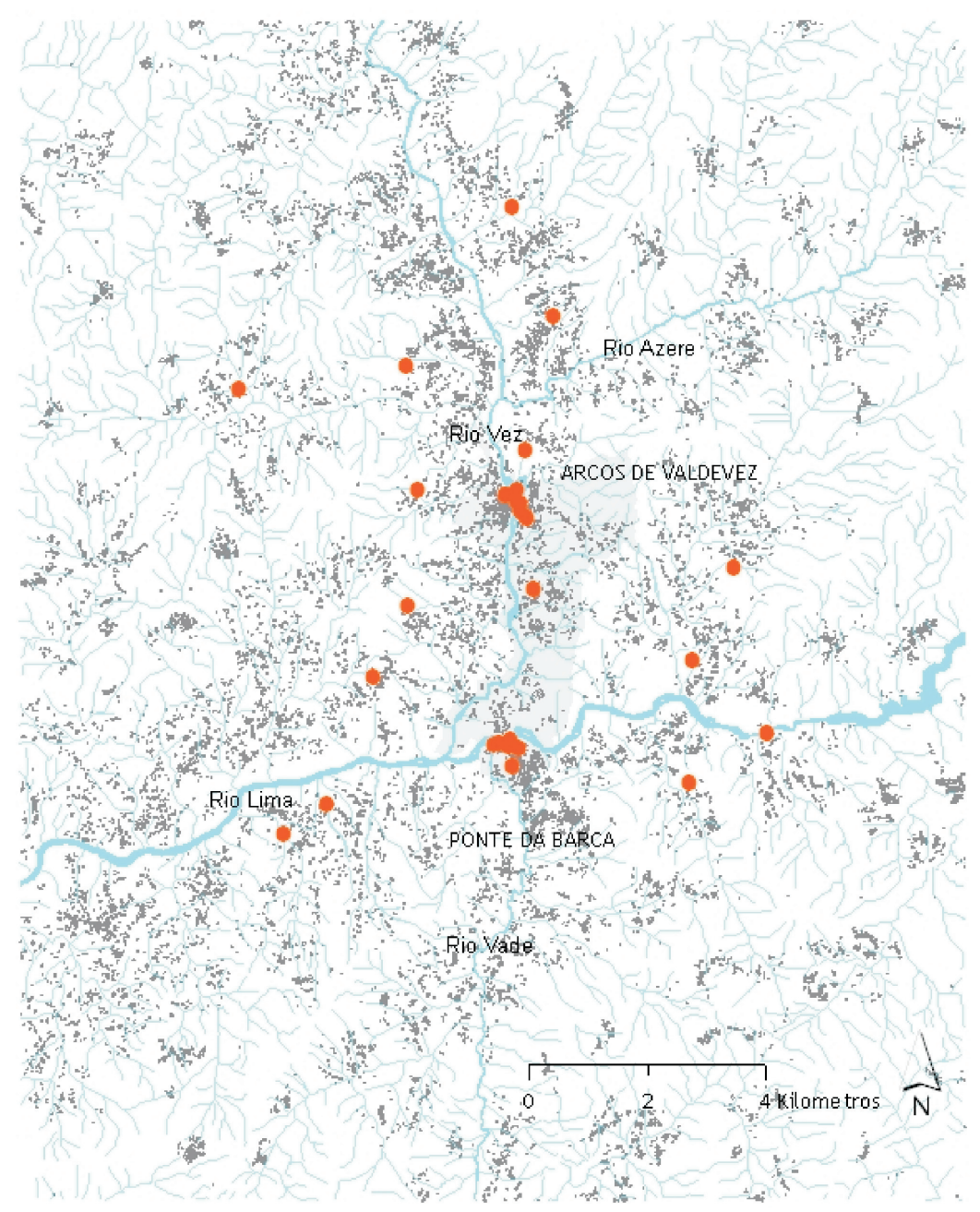

Fig. 1 - Localização histórico-geográfica dos danos devido a inundações. Fonte: Carta Militar de Portugal, escala 1:25000, Folhas 16 e 29, 1996/7. 
Em Arcos de Valdevez os danos decorreram principalmente na Valeta e em menor porte no Trasladário (avenida principal da vila). Na Valeta, o problema manifestou-se devido à falta de escoamento das águas da Ribeira de Vila Fonche (que desagua no Vez na Praia da Valeta), embora hoje já canalizado e prolongado o canal para desaguar mais afastado do bairro da Valeta. Nos dias de crise verificava-se refluxo das águas no túnel que liga o bairro da Valeta à Praia da Valeta, acabando por inundar aquela área (G. GonçAlves, 2009). No Trasladário, os danos verificaramse em estruturas públicas e principalmente queda de árvores existentes nessa avenida.

Em Ponde da Barca, foi no Curro e no Jardim dos Poetas (localizados na margem do Lima) da sede daquela vila, onde os danos foram mais problemáticos. No Curro, as habitações, casas comerciais, edifícios históricos e parque de estacionamento sofreram danos quando ocorreram inundações. No Jardim dos Poetas, os danos foram principalmente nas áreas verdes (relvado), estruturas públicas, para além de afectar alguns edifícios ali existentes, principalmente o Bar do Rio.

Os maiores problemas devido a inundações ribeirinhas aconteceram em habitações, comércio e vias de comunicação (ver Fig. 2). Os acontecimentos não foram significativos em algumas variáveis descritas, devido ao desenvolvimento naquela época. Só com a evolução de todo o contexto económico ocorreu um aumento significativo, de edifícios em áreas ribeirinhas, em infraestruturas e acessos e mesmo dos serviços (esgotos, telefone, electricidade, gás e sistema de abastecimento de água). A sua inexistência também não seria possível registar como dano. Podemos comparar os tempos actuais onde a população já está bem servida a nível de serviços, acessos e habitações enquanto que em 1909, quando ocorreu uma das maiores inundações, os bens eram muito escassos e a sua maior fonte de riqueza vinha da agricultura.

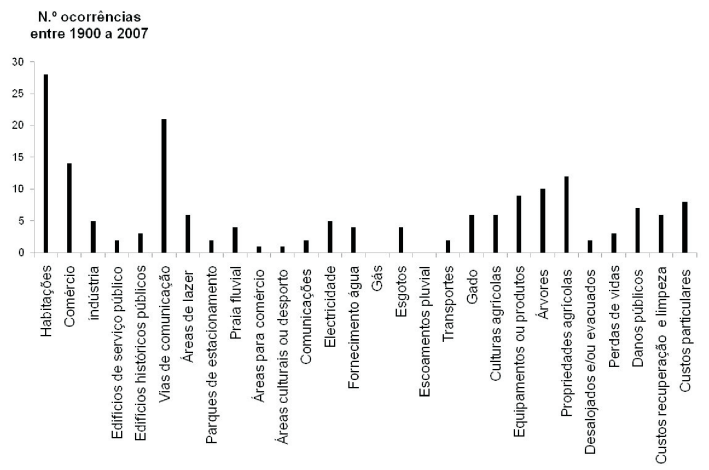

Fig. 2 - Tipologia dos danos em função das variáveis. Fonte: GonçALVES, 2009.
Para analisar a relação entre as perdas de vidas humanas e as características da inundação é necessário especificar a unidade territorial onde se deu o incidente (S. Jonkman, et al, 2008). Daí a importância da subdivisão do território a analisar em unidades territoriais de risco (A. Fernandez, 2008). A estimativa da perda de vidas humanas por evento pode ser obtida com base em três elementos: (1) a intensidade dos efeitos físicos e a superfície da área exposta; (2) o número de pessoas expostas (por vezes reduzido devido à evacuação, realojamento e salvamento); (3) a mortalidade entre as pessoas expostas (G. TSAKIRIS, et al, 2009). As perdas de vidas humanas registadas na área de estudo, foram algumas, como se pode observar na Fig. 2. Estas, ocorreram, segundo os periódicos, por afogamento em moinhos de que eram proprietários, outros morreram na travessia de pontilhões que ruíram devido à quantidade de água nos dias de cheias.

As áreas localizadas em redor da área alagada mas que não foram afectas pelas águas, podem ser atingidas por danos indirectos devido à existência de perdas de produção e distúrbios comerciais (G. TsAKIRIS, et al, 2009) pela limitação da circulação em áreas inundadas.

A dimensão dos danos reflecte-se especialmente na altura atingida pelas águas devido às inundações. Nas fotografias (Fot.1 a Fot. 4), apresentamos algumas das imagens de 1999 e 2001 onde podemos percepcionar a dimensão dos danos, à priori, aquando as inundações de 1999 e 2001.

Nem todos os danos podem ser calculados em termos de valor, pois, como refere M. MACHADO, et al, (2005) existe dificuldade em estabelecer um procedimento monetário do dano. Os mais difíceis de contabilizar serão os danos indirectos. J. BARREDO (2009) mostrou que não há nenhuma evidência de uma clara tendência positiva em danos causados por inundações na Europa. Supondo que o clima mantém-se, os danos por inundação continuaram a aumentar em consequência dos factores económicos e sociais.

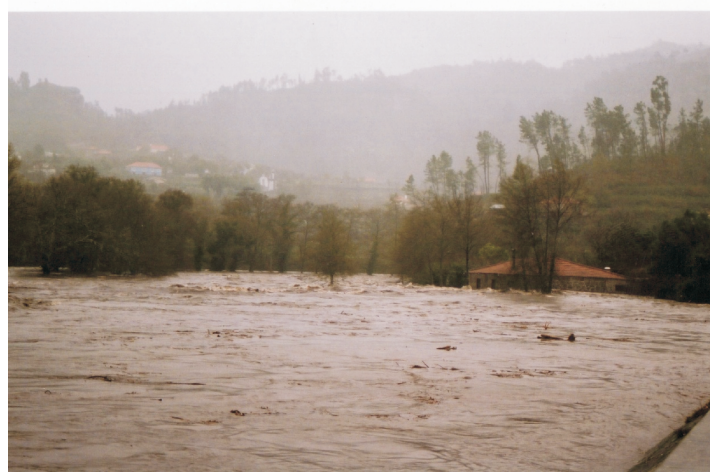

Fot. 1 - Inundação em 2001, na Praia da Valeta em Arcos de Valdevez. Ao fundo está localizado a Azenha Bar com a água até à cobertura (telhado) (R. Aguiam, 2008) 


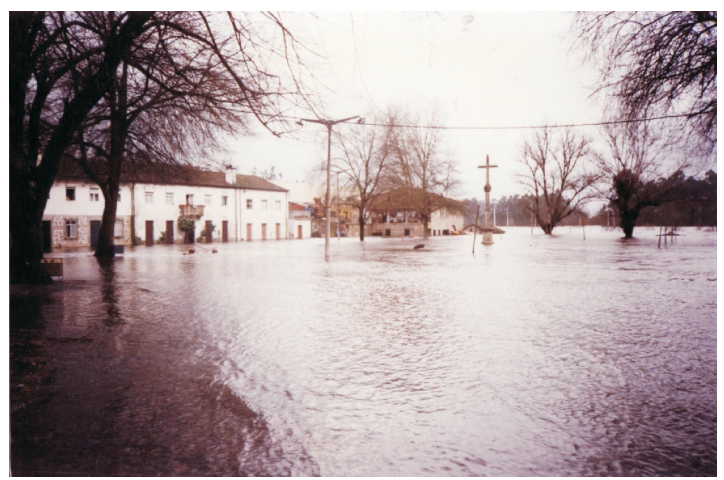

Fot. 2 - Inundação em 2001, no Curro em Ponte da Barca. Vemos na fotografia os edifícios inundados e todo o parque de estacionamento coberto pelas águas (NOTíCIAS DA BARCA, 2001)

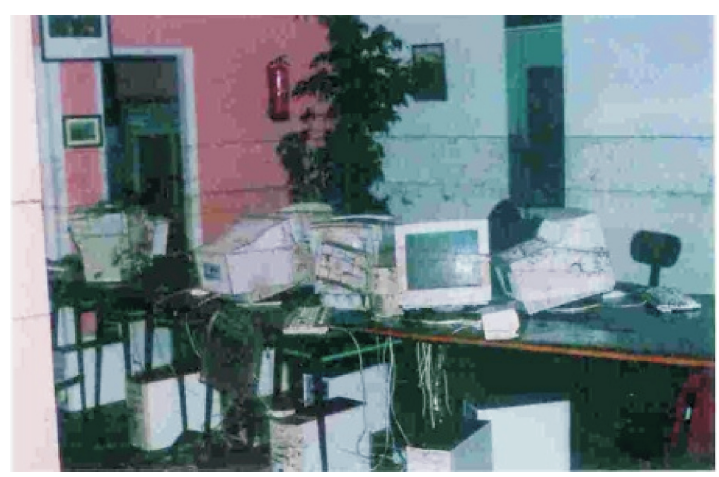

Fot. 4 - Danos nos equipamentos ocorridos após inundação de 1999, na Junta de Freguesia de Arcos São Salvador, localizada na Valeta (R. Aguiam, 2008)

\section{Magnitude dos danos}

Dos registos que foram recolhidos nos periódicos apresentamos graficamente a magnitude, considerando uma escala de 1 (ligeiro) a 4 (Extremo) e o número de vezes em que foram atingidos os vários "bens" privados e públicos. Como seria de esperar, o nível máximo da magnitude dos danos ocorrido durante cerca de um

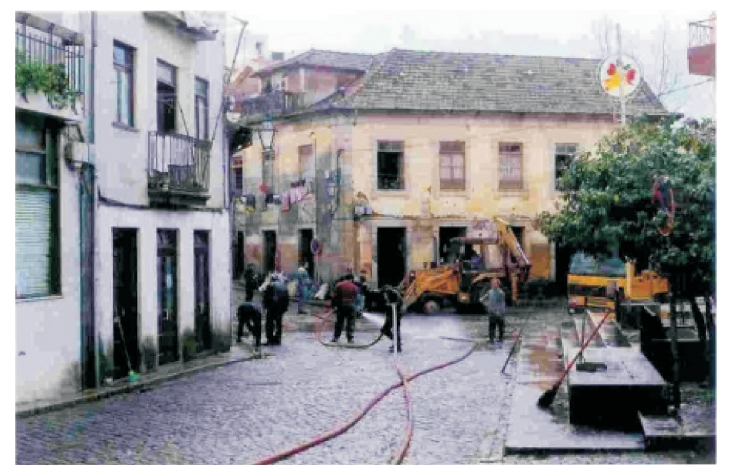

Fot. 3 - Limpeza dos arruamentos e edifícios da AD Valeta após a inundação de 1999. Pode-se observar os edifícios danificados nas fachadas, portas e, como se depreende, no seu interior

(R. AgUiam, 2008)

século, manifestou-se, em habitações, comércio e vias de comunicação (Fig. 3). No entanto, foram ainda registados valores extremos para danos em infraestruturas públicas (danos públicos) e privadas e houve a necessidade de proceder à recuperação e limpeza das áreas afectadas. Devido à situação, será importante contabilizar (somar aos anteriores danos) os gastos públicos e privados na reestruturação e reposição da situação normal que poderíamos considerar como “perda” indispensável.

Dos vários cenários registados, 31\% tiveram uma classificação do cenário com magnitude extrema e 32\% da magnitude foi classificada como de grau alto. Valores, estes, importantes para a percepção do registo dos cenários, onde, mais de metade dos eventos registados nos periódicos (de 1900 a 2007) foram de grau alto a extremo (Fig. 4).

O registo destes dados é importante para termos a percepção do risco nas áreas em estudo, o que permitirá no futuro um ordenamento do território mais regrado quanto a possíveis inundações. Neste sentido,

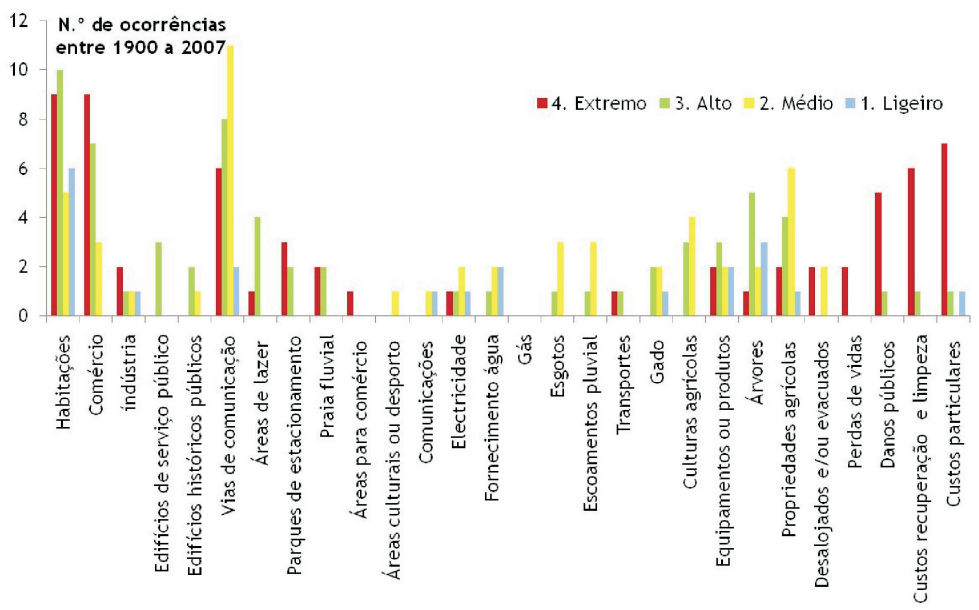

Fig. 3 - Magnitude dos danos devido a inundações. Fonte: G. Gonçalves, 2009. 


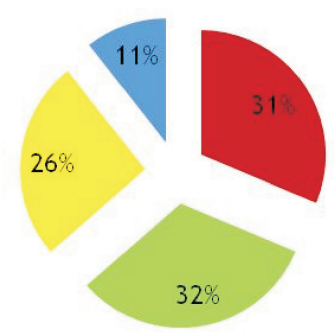

- 4. Cenário Extremo

3. Cenário Alto

2. Cenário Médio

1. Cenário Ligeiro

Fig. 4 - Resultado dos cenários perante a magnitude dos danos. Fonte: G. GonçaLVEs, 2009.

a percepção do risco por parte da comunicação social nos permite fazer uma análise simples e empírica para trabalharmos melhor a forma de comunicar os eventos. A qualidade da informação e o seu pormenor irá facilitar a análise pelos investigadores.

\section{Principais causas da dimensão dos danos}

As principais causas da origem dos danos estão relacionadas com a altura das águas dentro de edifícios e também com o número de construções existentes nos centros urbanos, mais propriamente junto às margens ribeirinhas. Os danos ocorridos são proporcionais à altura da água dentro de edifícios e fora, nos arruamentos, vias de comunicação, parques de estacionamento, áreas culturais e terrenos agrícolas. Dentro de edifícios, o nível da água nos pisos dos edifícios influencia os danos, dependendo da ocupação dos mesmos principalmente no primeiro piso. Quanto mais edifícios existirem em área de leito de cheia maiores serão os danos e a altura da água poderá ser maior devido à falta de escoamento e à impermeabilização do solo.

No gráfico (Fig. 5), podemos observar a altura das águas dentro dos edifícios medida desde o nível da rua. Por várias vezes, as águas entraram nos edifícios e inundaram acima dos 0,5 metros. A inundação de 1999 foi a que atingiu maior altura das águas nos edifícios, na Valeta (Arcos de Valdevez). Outras inundações importantes, foram as de 1987, 2000 e 2001, atingindo níveis acima de 1,5 metros de altura.

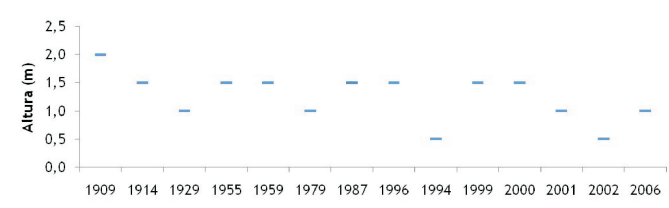

Ano

Fig 5. Nível das águas atingido dentro de edifícios medido desde a rua, em Arcos de Valdevez. Fonte: G. Gonçalves, 2009.
Comparativamente, a inundação de maior magnitude em Ponte da Barca, foi a de 1909, onde as águas dentro de edifícios rondaram os 2 metros de altura (Fig. 6). As inundações que se sucederam atingiram magnitudes mais reduzidas mas não deixaram de causar preocupação, com as águas nos edifícios niveladas por 1,5 metros. Outras, foram ainda de menor magnitude mas os danos foram muitos.

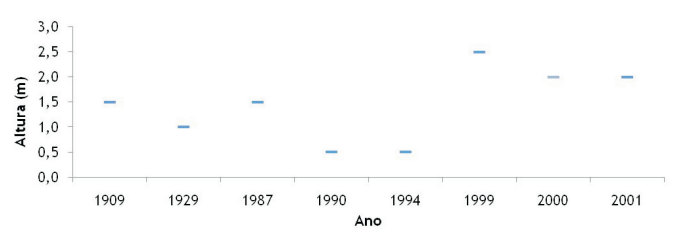

Fig 6. Nível das águas atingido dentro de edifícios medido desde a rua, em Ponte da Barca. Fonte: G. Gonçalves, 2009.

Os fogos construídos são uma das causas principais da dimensão dos danos ocorridos. Desde a adesão de Portugal à União Europeia o número das construções e formas de vida das populações foi evoluindo devido à facilidade de acesso ao poder económico, quer a nível de empréstimos bancários, quer a nível de ajudas económicas comunitárias. Com estes factos, a população sente necessidade de ampliar os seus espaços construídos, o que levou à impermeabilização dos solos, logo, à dificuldade de escoamentos das águas pluviais, especialmente em dias de cheias. Podemos constatar, na Fig. 7, segundo dados recolhidos no INSTITUTO NACIONAL DE ESTATÍSTICA (INE), que a partir dos anos oitenta o número de fogos construídos cresceu exponencialmente nas quatro freguesias dos centros urbanos das duas vilas (as três freguesias que fazem parte da Vila de Arcos de Valdevez, Arcos de Valdevez S. Salvador, Arcos de Valdevez S. Paio e Paçô; e a Freguesia de Ponte da Barca).

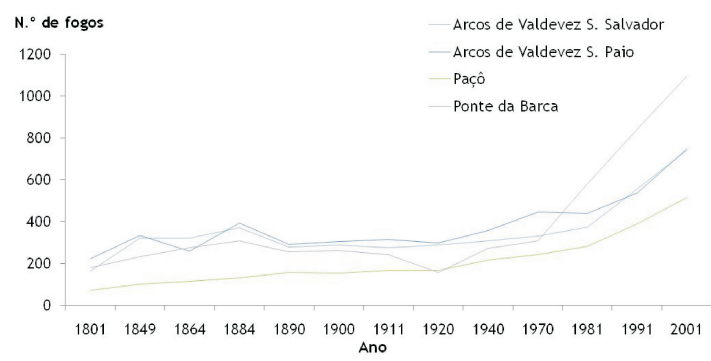

Fig. 7 - Distribuição dos fogos nas quatro freguesias dos centros urbanos dos dois concelhos. Fonte: "Base de dados" on-line, “Censos”, INE, 1801 a 2001 (adaptado).

As inundações são responsáveis por danos provavelmente mais que todos os outros eventos naturais destrutivos combinados. Além disso, os meios financeiros gasto pelas sociedades de todo o mundo em controle de inundações é um múltiplo de custos (W. Kron, 2005). Nos tempos antigos, a maioria dos bens foram pouco sensíveis a 
danos devido a inundações. Os pertences existentes puderam ser levados para um local seguro e, mesmo que fossem perdidos, o dano foi relativamente pequeno. Hoje, muitas vezes dentro dos edifícios verificam-se danos após inundação. Especialmente, os equipamentos eléctricos e mecânicos, aparelhos e outros dispositivos são altamente vulneráveis a humidade e a sujidade e outras partículas de poluição, que sempre são encontradas em águas da inundação (W. KRON, 2005). Não obstante, um evento específico pode não ser significativo em termos de danos em escala global, mas pode ser dramático em escala regional a local, ao expor a população ao risco de perdas de vida, propriedades, culturas e outros prejuízos financeiros, além de risco a cortes de energia, contaminação de água potável e ocorrência de várias doenças, inclusive psíquicas, muitas vezes de difícil recuperação.

\section{Conclusão}

- A percentagem dos danos aumenta com o aumento da área construída afectando em especial as habitações e vias de comunicação;

- Os periódicos como fonte de informação são importantes a nível da percepção do risco de inundação embora para quantificar os danos sente-se muita carência de dados relevantes;

- É necessário recolher junto de outras fontes nacionais informação para podermos minimizar o risco da perda e comparar bases de dados e apurá-la.

- É necessário comparar a base de dados com informação meteorológica.

Os resultados sobre os danos obtidos influenciados pelas características das inundações devem ser consideradas como indicativos. Recomenda-se a recolha de dados mais precisos, a população afectada e as características das inundações. Eventualmente, com base em análises mais completas e com metodologias melhoradas para podermos estimar os danos com mais rigor. Apesar das limitações, os resultados apresentados dão uma introspecção importante na relação entre os danos ocorridos e as características das inundações, nomeadamente a altura da água atingida dentro de edifícios. Estas percepções podem ser utilizadas para análise de risco e como contributo para a tomada de decisões no ordenamento do território.

Para o edificado, deve ser assumido um custo de construção e os custos esperados em repor os danos. Conhecer os benefícios e as perdas e em particular a ameaça às vidas humanas. Outro factor é ter em atenção os habitats ameaçados para que os decisores façam a análise antes de implementar os empreendimentos ( $\mathrm{L}$. NunEs, 2009).
As inundações, em particular, geram perdas económicas compatíveis com a sua alta incidência. Destaca-se, que elas acontecem em qualquer local do globo, sendo independente do tipo climático e apenas parcialmente dependente de variáveis físicas, como a precipitação (L. NunEs, 2009).

\section{Agradecimentos}

Este trabalho foi realizado com base na informação da Tese de Mestrado em Riscos, Cidades e Ordenamento do Território, apresentado em Setembro de 2009 na Faculdade de Letras da Universidade do Porto. Neste sentido, agradece-se a todos que contribuíram para a publicação deste trabalho.

\section{Referências bibliográficas}

Aguiam, Rui, F. G., 2008. Cheias da Valeta. Comunicação interpessoal, disponibilização de fotografias, Junta de Freguesia de Arcos Salvador, Setembro e 2008.

BARREDO, José. I., 2009. Normalised flood losses in Europe: 1970 - 2006. Natural Hazards and Earth System Sciences, 9, 97-107.

Fernández, Maria. A., 2008. Metodologia para la lectura de escenarios de riesgo, Master Degree on Natural and Human Environmental Studies, Faculty of Geography and History, Salamanca University.

GonÇALVES, Gloria., 2009. Áreas Inundáveis entre 1900 a 2007 em Arcos de Valdevez e Ponte da Barca, Portugal, Mestrado em Riscos, Cidades e Ordenamento do Território, Universidade do Porto.

INE, 1801 a 2001. Anuário Estatístico da Região Norte. Instituto Nacional de Estatística, Censos, base de dados on-line, URL: www.ine.pt.

EGeoE, 1996. Carta Militar de Portugal. Instituto Geográfico do Exército, escala 1:25000, Filha 16, 1996.

EGeoE, 1997. Carta Militar de Portugal. Instituto Geográfico do Exército escala 1:25000, Filha 29, 1997.

Jonkman, S. N., et al, 2008. Loss of life caused by the flooding of New Orleans after hurricane Katrina: a preliminary analysis of the relationship between flood characteristics and mortality. $4^{\text {th }}$ International Symposium on Flood Defence, Managing Flood Risk, Reliability and Vulnerability, Toronto, Ontario, Canada, May 6-8, 2008, pp. 96-1 a 96-9, p. 96-6. 
HAQUE, C. Emdad., 2000. Risk Assessment, Emergency Preparedness and Response to Hazards: The case of the 1997 Red River Valley Flood, Canada. Natural Hazards, 21, 224-245, p 226.

KREIBICH, H. et al, 2005. Flood loss reduction of private households due to building precautionary measures - lessons learned from the Elbe flood in August 2002. Natural Hazards and Earth System ciences (2005) 5: 117-126, p 117.

KRON, Wolfgang, 2005. Flood = Hazard. Values . Vulnerability. International Water Resources Association. Water International, V. 30, N. ${ }^{\circ} 1$, pag. 58-68, Março 2005.

MACHADO, Maria. L, et al, 2005. Curvas de inundação versus profundidade de submersão: desenvolvimento de metodologia. REGA, Vo. 2, N. ${ }^{\circ} 1$, P. 35-52,
Jan./Jun. 2005.

NunEs, Lucí. H., 2009. Compreensões e acções frente aos padrões espaciais e temporais de riscos e desastres. V Encontro Nacional, I Congresso Internacional de Riscos, Territorium, 16, 179189; Maio de 2009, p.183, 184.

Pellegrina, G. J., et al, 2009. Elaboração de um banco de dados para eventos severos. Territorium, 16, 33-36, Revista da Associação Portuguesa de Riscos, Prevenção e Segurança.

TSAKIRIS, G., et al, 2009. Critical Technical Issue on the EU Flood Directive. EWRA, European Water, 25/26: 39-51, 2009, EW, Publications. 